\title{
Review uncovers fatal flaws in long-term care infection control
}

- Cite as: CMAJ 2020 October 13;192:E1221-2. doi: 10.1503/cmaj.1095899

Posted on cmajnews.com on September 22, 2020

A review into 53 deaths at Nova Scotia's largest long-term care facility highlights critical staff shortages, problems isolating residents infected with severe acute respiratory syndrome coronavirus 2 (SARS-CoV-2), and difficulty accessing infection control specialists during the first wave of the coronavirus disease 2019 (COVID-19) pandemic.

The provincial government released an executive summary and 17 recommendations stemming from the review, and a report looking at infection control across the long-term care system. Nova Scotia will spend $\$ 26$ million now and $\$ 11$ million over the next two years to implement the recommendations.

"The review itself will in no way make up for what transpired in Northwood," said Nova Scotia Health Minister Randy Delorey at a news conference. "It will never take away the pain, and it won't bring back what was lost."

Between April 5 and May 26, 360 residents and staff at Northwood tested positive for SARS-CoV-2, with some showing COVID-19 symptoms as early as March 31. During the outbreak, the province faced criticism for failing to communicate clearly about infections at the site and moving too slowly to isolate cases. Eventually, residents who recovered from COVID-19 moved offsite to free up rooms to isolate others.

According to the review, the size and complexity of the 500-bed facility made Northwood "especially susceptible to staff loss and infection spread."

Staffing shortages, inconsistent cleaning, shared rooms and bathrooms, and limited control of the temperature, humidity and ventilation were critical

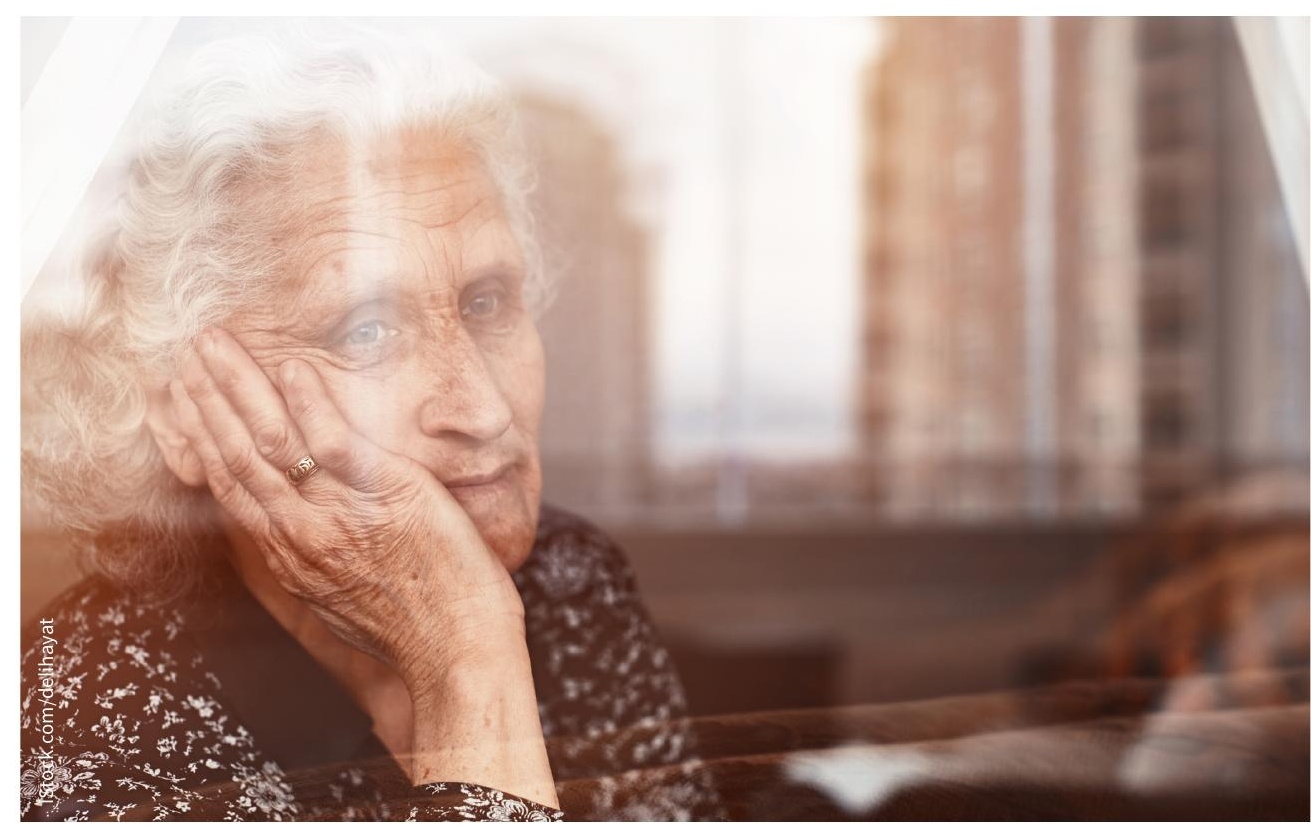

Long-term care facilities must balance the risk of COVID-19 against residents' quality of life, according to a review into an outbreak in Nova Scotia.

factors in the outbreak. And because of a breach in Northwood's online system before the pandemic, officials were using pen and paper to track staff levels.

The provincial government's review recommends permanently reducing the number of residents living at Northwood and setting aside space to isolate infected people during future outbreaks. Pandemic plans should be updated to set a threshold at which losing staff triggers a call to the provincial government for help. The review also suggests designating housekeeping staff as critical support workers.

Other recommendations for the facility, health system and government include:

- Creating a communication plan to let residents, families and staff know what information they'll get in an emergency, and when;

- Improving ventilation in bathrooms;

- Setting and funding a minimum number of hours of direct care;

- Increasing supplies of protective equipment for long-term care staff;

- Establishing a mobile infection control team and ensuring that disaster response teams have the power to override "obstructive" legislation;

- Increasing support for medical officers of health for contact tracing and analytic modelling; and

- Mandating the collection, reporting and analysis of morbidity and mortality data by facility.

Many of the concerns highlighted in the report are common across Canadian longterm care facilities. While Canada's overall 
death rate from COVID-19 was relatively low compared to other Organisation for Economic Co-operation and Development nations, it had the highest proportion of deaths occurring in long-term care facilities at $81 \%$.

Other countries that accounted for long-term care staffing and incentivization in pandemic plans had "better outcomes," said Dr. Chris Lata, an infectious disease expert and co-author of the Northwood review.

Balancing the risk of COVID-19 with residents' quality of life is another critical factor for the sector to grapple with. "There is no such thing as zero risk," Lata said. "A lot of those residents missed an entire summer. They were stuck in their rooms."

The review recommends easing pandemic precautions to allow residents to move around, leave the facility with family, and receive visitors, food and personal items. "Some of those residents will not survive to see another summer, and that has to be considered in the balance," Lata said.

Despite the review's emphasis on transparent communication, Nova Scotia's provincial government did not release the full details of the report and has rejected calls for a full public inquiry, something which concerned Progressive Conservative Leader Tim Houston.

"The format of the review seems designed to protect the province from embarrassing revelations on issues such as whether sufficient protective gear was available to staff," he said in a statement. "For me, a public inquiry equals transparency, openness and has binding recommendations."

Laura Eggertson, Wolfville, N.S. 